\title{
Is there a duty to recontact in light of new genetic technologies? A systematic review of the literature
}

\author{
Ellen Otten, $\mathrm{MD}^{1}$, Mirjam Plantinga, $\mathrm{PhD}^{1}$, Erwin Birnie, $\mathrm{PhD}^{1}$, Marian A. Verkerk, $\mathrm{PhD}^{2}$, \\ Anneke M. Lucassen, $\mathrm{PhD}^{3,4}$, Adelita V. Ranchor, $\mathrm{PhD}^{5}$ and Irene M. Van Langen, $\mathrm{PhD}^{1}$
}

\begin{abstract}
Purpose: With rapid advances in genetic technologies, new genetic information becomes available much faster today than just a few years ago. This has raised questions about whether clinicians have a duty to recontact eligible patients when new genetic information becomes available and, if such duties exist, how they might be implemented in practice.
\end{abstract}

Methods: We report the results of a systematic literature search on the ethical, legal, social (including psychological), and practical issues involved in recontacting former patients who received genetic services. We identified 1,428 articles, of which 61 are covered in this review.

Results: The empirical evidence available indicates that most but not all patients value being recontacted. A minority of (older) articles conclude that recontacting should be a legal duty. Most authors consider recontacting to be ethically desirable but practically unfeasible. Various solutions to overcome these practical barriers have been proposed, involving efforts of laboratories, clinicians, and patients.

Conclusion: To advance the discussion on implementing recontacting in clinical genetics, we suggest focusing on the question of in what situations recontacting might be regarded as good standard of care. To this end, reaching a professional consensus, obtaining more extensive empirical evidence, and developing professional guidelines are important.

Genet Med advance online publication 11 December 2014

Key Words: clinical genetics; duty to recontact; ethical, legal, and social (including psychological) issues; next-generation technologies; professional and patient perspectives

\section{INTRODUCTION}

Next-generation sequencing technologies are rapidly being introduced into clinical genetic practice. The level of detail at which a person's genetic code can now be analyzed is several thousand times greater than it was just a few years ago, and the costs are decreasing rapidly. Patients seen in the past may have had genetic testing that could now be improved on, whereas for patients who undergo newer testing, the interpretation of clinical diagnoses or predictions may evolve over time. What duties do clinicians have to these patients? This is not a "oneoff" problem because the development of genetic testing techniques progresses on an exponential scale. Genetic testing for previously unknown genes may now be available, or results that were previously uninterpretable may now be recognized as pathogenic, with clinical surveillance or even treatment being possible. New, actionable information could change medical policies for patients and offer opportunities for family screening, prevention, and new reproductive choices.

The potential for recontacting in clinical genetics raises several ethical, legal, and social (including psychological) issues (ELSI). For example, which new information justifies recontacting? Would recontacting in clinical genetics always be beneficial? How would such activities respect patients' privacy and their putative right not to know? Should recontacting be made a legal obligation? If so, could clinicians face liability claims if they fail to recontact former patients? What practical issues might clinicians face when trying to recontact former patients? And how could these be solved? Who would be responsible for recontacting? What are patients' views on these issues? How is the changing landscape of clinical genetics and communication technologies shaping the debate about a possible duty to recontact? Although many of these questions have been discussed in the literature, there is no overview of what has been published so far. We therefore conducted a systematic review of the literature investigating these issues and of the empirical evidence available. Our results can serve as a starting point for further research and for the possible development of professional guidelines on recontacting in clinical genetic practice.

\section{MATERIALS AND METHODS}

\section{Definition of duty to recontact in clinical genetics}

We defined the duty to recontact as the ethical and/or legal obligation to recontact former patients about new genetic information. We specifically wanted to explore situations without a current relationship between a health-care professional (HCP) and a patient/client, so we excluded situations in which a treatment relationship was ongoing or recontacting was described in a research setting rather than a clinical setting.

${ }^{1}$ Department of Genetics, University Medical Center Groningen, University of Groningen, Groningen, The Netherlands; ${ }^{2}$ Department of Internal Medicine, University Medical Center Groningen, University of Groningen, Groningen, The Netherlands; ${ }^{3}$ Faculty of Medicine, Clinical Ethics and Law, University of Southampton, Southampton, UK; ${ }^{4}$ Wessex Clinical Genetic Service, Southampton, UK; ${ }^{5}$ Department of Health Psychology, University Medical Center Groningen, University of Groningen, Groningen, The Netherlands. Correspondence: Ellen Otten (e.otten@umcg.nl.) 


\section{Literature search strategy}

We systematically searched the literature on the duty to recontact in clinical genetic practice in four databases: PubMed, Embase, Web of Science, and Google Scholar. In our search strategy we used the key term "genetic," combined by Boolean operators with either the (MeSH) term "duty to recontact" or one of the following synonyms: "duty/obligation/responsibility to warn," "duty/obligation/responsibility to disclose," "duty/ obligation/responsibility to recall," and "duty/obligation/ responsibility to re-contact." We included all articles published before 1 September 2014 that contained these search terms in their title or abstract (PubMed, Embase), in their title or topic (Web of Science), or in the whole text (Google Scholar).

\section{Selection of papers}

The search was performed by two of the authors (E.O., M.P.); it identified 1,428 articles in total (Figure 1). After reading the titles and abstracts, we excluded 1,253 articles because they (i) did not discuss recontacting at all $(n=509)$; (ii) did not discuss recontacting in clinical genetics but in a research setting $(n=$ 333); or (iii) did not discuss recontacting former patients but informing patients' family members or third parties $(n=411)$. When there was any doubt about excluding an article, it was discussed until the two researchers reached agreement. We selected 175 articles for further analysis. Another 58 articles were added by tracking reference lists. After removing duplicates $(n=132)$ and excluding abstracts of poster or oral presentations $(n=7)$, articles that were not available as full text $(n=13)$, and those that were not written in English $(n=3), 78$ articles remained.

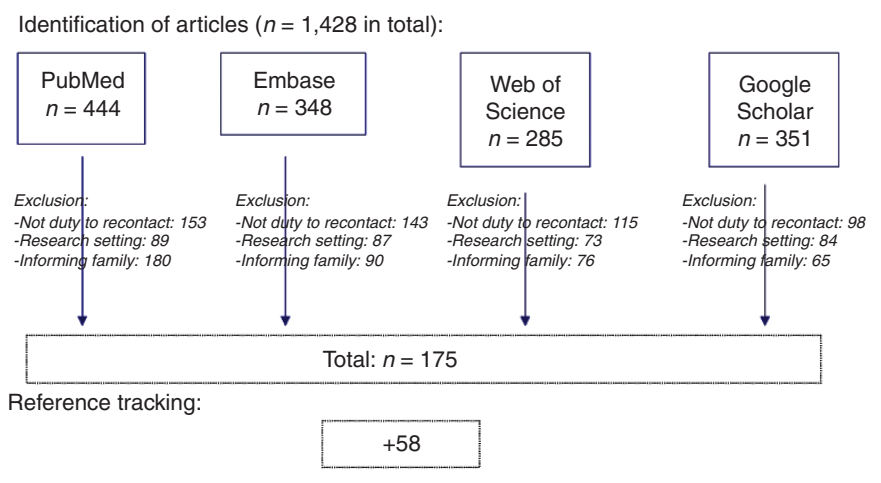

Total after duplicates $(n=132)$ removed:

$$
n=101
$$

Total after exclusion of full text not available $(n=13)$, abstract of poster/oral presentation $(n=7)$, and non-English language $(n=3)$ :

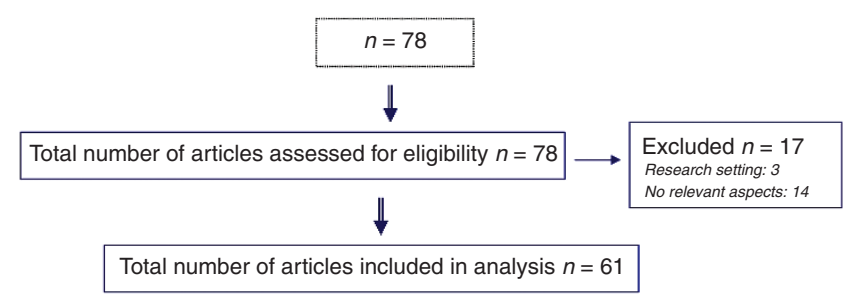

Figure 1 Literature search results for duty to recontact in clinical genetics.

\section{Analysis}

All 78 articles were analyzed independently by two researchers (M.P., E.O.) based on the following eight aspects: (i) From which discipline-specific viewpoints is the duty to recontact discussed (ethical, legal, social, clinical)?; (ii) In which situations is/should recontacting be performed?; (iii) Which ELSI and practical issues, for and against a duty to recontact, are put forward?; (iv) Which practical barriers and solutions are being discussed?; (v) What conclusion about a duty to recontact is drawn (duty/no duty/not defined)?; (vi) Whose duties are being discussed (laboratory, treating HCP, referring HCP, patient)?; (vii) Is the article written from a theoretical perspective or based on empirical evidence (practical experience/surveys/ focus groups) and, if yes, what was the empirical evidence?; and (viii) Do the selected articles mention or make use of any guidelines on the duty to recontact?

After full-text analysis, we excluded another 17 articles because they did not discuss recontacting after all $(n=14)$ or were about recontacting in a research setting only $(n=3)$. We eventually included 61 articles in the review. ${ }^{1-61}$ Most of the literature was from the United States (54\%), followed by Canada (20\%), Europe (20\%), Australia (3\%), India (1.5\%), and Israel (1.5\%) (Table 1).

All articles were scored using the eight predetermined aspects covering the main ELSI-related issues discussed in the literature. The scoring system was tested for robustness by four researchers who independently scored seven of the articles, varying with respect to year of publication, discipline, and research type. When scoring all 61 articles, we restricted ourselves to the information given in the articles, which meant that not all the articles could be scored on all aspects. Disagreements on the scoring were discussed until a consensus was reached by the two analyzing researchers and a third independent researcher (I.M.V.L.).

\section{RESULTS \\ Duty to recontact in clinical genetics: discussion by discipline}

The earliest publications about a duty to recontact in clinical genetics date from the 1990s (Table 1). They were all from the United States and Canada, except one, and half of these articles addressed a duty to recontact from a legal perspective. Over time, the contributions from other countries increased, the number of legal discussions decreased, and the number of contributions that addressed an ethical perspective increased. An author from a clinical center was involved in more than $80 \%$ of the articles, so in the empirical as well as in most of the theoretical articles, the aspects discussed were seen, at least in part, through "clinical eyes." Contributions primarily written by health psychologists were scarce, although psychological aspects were mentioned in a substantial number of papers. There were no clear differences between opinions of authors from different countries or disciplines.

In the more recent literature (since 2008), a duty to recontact is often discussed in light of the introduction of next-generation 
Table 1 Articles included in the review, by country and by discipline

\begin{tabular}{|c|c|c|c|c|c|c|c|}
\hline \multirow[b]{2}{*}{ Reference } & \multirow[b]{2}{*}{ First author } & \multirow[b]{2}{*}{ Year of publication } & \multirow[b]{2}{*}{ Region } & \multicolumn{4}{|c|}{ Discipline(s) } \\
\hline & & & & Ethical & Legal & Social & Clinical \\
\hline 1 & Pelias & 1991 & USA & - & + & - & + \\
\hline 2 & Andrews & 1991 & USA & - & + & - & - \\
\hline 3 & Andrews & 1992 & USA & - & + & - & - \\
\hline 4 & Hecht & 1992 & USA & - & - & - & + \\
\hline 5 & Pelias & 1992 & USA & - & + & - & + \\
\hline 6 & Patenaude & 1996 & USA & - & - & + & - \\
\hline 7 & Almqvist & 1997 & Canada & - & - & - & + \\
\hline 8 & Andrews & 1997 & USA & - & + & - & - \\
\hline 9 & Bernard & 1999 & Canada & - & - & - & + \\
\hline 10 & Hirschhorn & 1999 & USA & - & - & - & + \\
\hline 11 & Sharpe & 1999 & Canada & - & - & - & + \\
\hline 12 & Fitzpatrick & 1999 & USA/Canada & - & - & - & + \\
\hline 13 & Harris & 1999 & Europe & - & - & - & + \\
\hline 14 & Dean & 2000 & Europe & - & - & - & + \\
\hline 15 & Hunter & 2001 & Canada & - & - & - & + \\
\hline 16 & Knoppers & 2001 & Canada & - & + & - & - \\
\hline 17 & Peshkin & 2001 & USA & - & - & - & + \\
\hline 18 & Godard & 2003 & Europe & - & - & - & + \\
\hline 19 & Wertz & 2003 & Europe & + & - & - & - \\
\hline 20 & Letendre & 2004 & Canada & + & + & - & - \\
\hline 21 & Doheny & 2004 & USA & - & - & - & + \\
\hline 22 & Milunsky & 2004 & USA & - & - & - & + \\
\hline 23 & Brown & 2006 & USA & - & - & - & + \\
\hline 24 & Guzauskas & 2006 & USA & + & - & - & + \\
\hline 25 & Kausmeyer & 2006 & USA & - & - & - & + \\
\hline 26 & Hunter & 2006 & Canada & - & - & - & + \\
\hline 27 & Nagaraja & 2006 & India & - & - & - & + \\
\hline 28 & Griffin & 2007 & USA & - & - & - & + \\
\hline 29 & Peshkin & 2007 & USA & + & - & - & + \\
\hline 30 & Sexton & 2008 & Australia & - & - & - & + \\
\hline 31 & Rubinstein & 2008 & USA & - & - & - & + \\
\hline 32 & Rantanen & 2008 & Europe & - & - & - & + \\
\hline 33 & Shirts & 2008 & USA & + & - & - & + \\
\hline 34 & Sexton & 2008 & Australia & - & - & - & + \\
\hline 35 & Hampel & 2009 & USA & - & - & - & + \\
\hline 36 & Mezer & 2009 & Israel & - & - & - & + \\
\hline 37 & Resta & 2009 & USA & - & - & - & + \\
\hline 38 & Ali-Khan & 2009 & Canada & - & - & - & + \\
\hline 39 & Dondorp & 2010 & Europe & + & - & - & - \\
\hline 40 & Elger & 2010 & Europe & + & - & - & - \\
\hline 41 & Pyeritz & 2011 & USA & - & - & - & + \\
\hline 42 & Sijmons & 2011 & Europe & - & - & - & + \\
\hline 43 & Sharp & 2011 & USA & + & - & - & - \\
\hline 44 & Murray & 2011 & USA & - & - & - & + \\
\hline 45 & Hastings & 2012 & Europe & + & - & - & + \\
\hline 46 & Trakadis & 2012 & Canada & - & - & - & + \\
\hline 47 & Aronson & 2012 & USA & - & - & - & + \\
\hline 48 & Thorogood & 2012 & Canada/Europe & + & - & - & + \\
\hline 49 & Townsend & 2012 & Canada & + & - & - & + \\
\hline 50 & Van El & 2013 & Europe & + & - & - & + \\
\hline 51 & Vanakker & 2013 & Europe & - & - & - & + \\
\hline 52 & Reiff & 2013 & USA & - & - & - & + \\
\hline 53 & Bean & 2013 & USA & - & - & - & + \\
\hline 54 & Clayton & 2013 & USA & + & + & + & + \\
\hline 55 & Hazin & 2013 & USA & + & - & + & + \\
\hline 56 & Quaid & 2013 & USA & + & - & - & + \\
\hline 57 & Ayuso & 2013 & Europe & - & - & - & + \\
\hline 58 & Hunt & 2013 & USA & + & - & - & - \\
\hline 59 & O'Connor & 2014 & USA & - & - & - & + \\
\hline 60 & Semaka & 2014 & Canada & - & - & - & + \\
\hline 61 & Wagner & 2014 & USA & - & - & - & + \\
\hline
\end{tabular}


technologies. These articles added two new dimensions to the original discussion about recontacting in clinical genetics: first, a discussion of the issues of large-scale incidental findings and variants of unknown significance (VOUS) associated with these new-generation technologies was initiated, and, second, the introduction and specific characteristics of direct-to-consumer genetic testing were added to the discussion in some articles. $^{33,41,48}$ These new developments are believed to further complicate recontacting in clinical genetics.

\section{Recontact in clinical genetics: in which situations?}

For each article, we analyzed the situations in which a duty to recontact was thought to apply (Table 2). We scored each article on whether one or more of four recontacting situations were mentioned: (i) new treatment option or screening recommendation; (ii) new technique or genetic test available; (iii) new laboratory information (e.g., new interpretation of former test results or new gene associated with a disease formerly tested for); (iv) VOUS. In 13 articles recontacting was discussed in light of new genetic information without defining what this new information entailed. Recontacting in situations in which new treatment options or screening recommendations were available was discussed in nine of the (mostly older) articles. In about $50 \%$ of the older articles, recontacting situations included the availability of new tests (e.g., direct testing for Huntington disease, FMR1 testing, BRCA1/2 large rearrangement testing) and, consequently, new genetic information being available to former patients. By contrast, the more recent articles did not discuss the availability of whole-genome sequencing (WGS) as a new test/technique but rather discussed the consequences of applying this new test/technique in relation to recontacting, in the sense of new laboratory information becoming available.

Most articles (36 in total, including all articles from 2011 onward) referred to the situation in which new laboratory information becomes available; the issues of changes in classification of monogenetic test outcomes from VOUS to known pathogenic or nonpathogenic outcomes or the expansion or reinterpretation of results from WGS based on extended knowledge were often raised (Table 2 ).

\section{ELSI issues regarding the duty to recontact}

ELSI, as well as practical issues, were raised when discussing whether recontacting should be considered a duty (Table 3 ). Ethical and legal issues were raised as arguments both in favor of and against a duty to recontact, whereas social and practical issues were mostly seen as counterarguments. Overall, counterarguments are discussed in the literature more often than arguments in favor of recontacting. This did not, however, lead authors to conclude that recontacting in clinical genetics is undesirable. Many articles, in fact, start by proposing that recontacting in clinical genetics is to some extent desirable. The arguments for why this is believed to be so are not always mentioned explicitly. Counterarguments, on the other hand, usually are mentioned explicitly. From the overview of pro and contra arguments (Table 3), one can therefore not (always) conclude whether authors are in favor of or against a duty to recontact in clinical genetics.

The ethical arguments that were most often cited on both sides of the discussion were respect for patient autonomy, beneficence (do good), and nonmaleficence (do no harm). Regarding patient autonomy, it was often reasoned that recontacting former patients with new actionable information may promote autonomy because such information may offer new opportunities to former patients. ${ }^{15}$ Another argument put forward regarding patient autonomy was that consent to be recontacted can never be truly autonomous because patients do not know what kind of information might be disclosed. ${ }^{20}$ The more recent literature relatively more often raised ethical arguments against a duty to recontact, thereby emphasizing respect for patient autonomy, which is thought to become even more important in light of WGS. ${ }^{49,54}$ Hunter et al. ${ }^{15}$ stated that there is a greater justification for recontacting former patients with definite, significant information about a life-threatening disease than for a small increased risk for a slowly progressive disease. They also noted that information may affect people differently, and therefore recontacting might be beneficial for some, whereas it might be harmful to others. The disease in question and the nature and timing of the information will most probably influence this impact.

Legal arguments for and against recontacting were raised primarily in the older articles. Liability issues were discussed most often. It was argued that recontacting could prevent professionals from being held liable for negligence by former patients, who might claim a need to know any new, medically relevant information. ${ }^{1,5,15,28,59}$ The opposite issue-that patients could sue their HCP because recontacting breached their right not to know-was not explicitly addressed in the literature, although the importance of a patient's right not to know was often mentioned. Liability was, however, discussed as a counterargument by Letendre and Godard, ${ }^{20}$ reasoning that professionals may make themselves vulnerable if they cannot satisfy the expectations raised by embracing a recontacting policy. In the more recent literature focusing on recontacting in relation to WGS, legal arguments are rarely discussed. With respect to the persistently increasing relevance of incidental findings from WGS, Clayton et al. ${ }^{54}$ stated that there is no existing case law and a duty to recontact is unlikely to extend in perpetuity or to require more than reasonable effort.

The social aspects of recontacting were addressed repeatedly (Table 3), mainly focusing on psychological issues. Psychological arguments in favor of recontacting were discussed in only three articles. According to Sharpe ${ }^{11}$ one can argue in favor of recontacting because it may correspond to "patients' informational, communicative, emotional, and psychological needs." Sexton and Metcalfe ${ }^{34}$ and O'Connor ${ }^{59}$ mentioned the reduction of uncertainty to patients as a psychological argument in favor of recontacting. In 15 articles the presumed psychological impact of recontacting was, however, put forward as an argument against imposing a duty. The main arguments comprised potentially increased anxiety, stress, and negative 
Table 2 Discussed duties in the clinical genetic setting

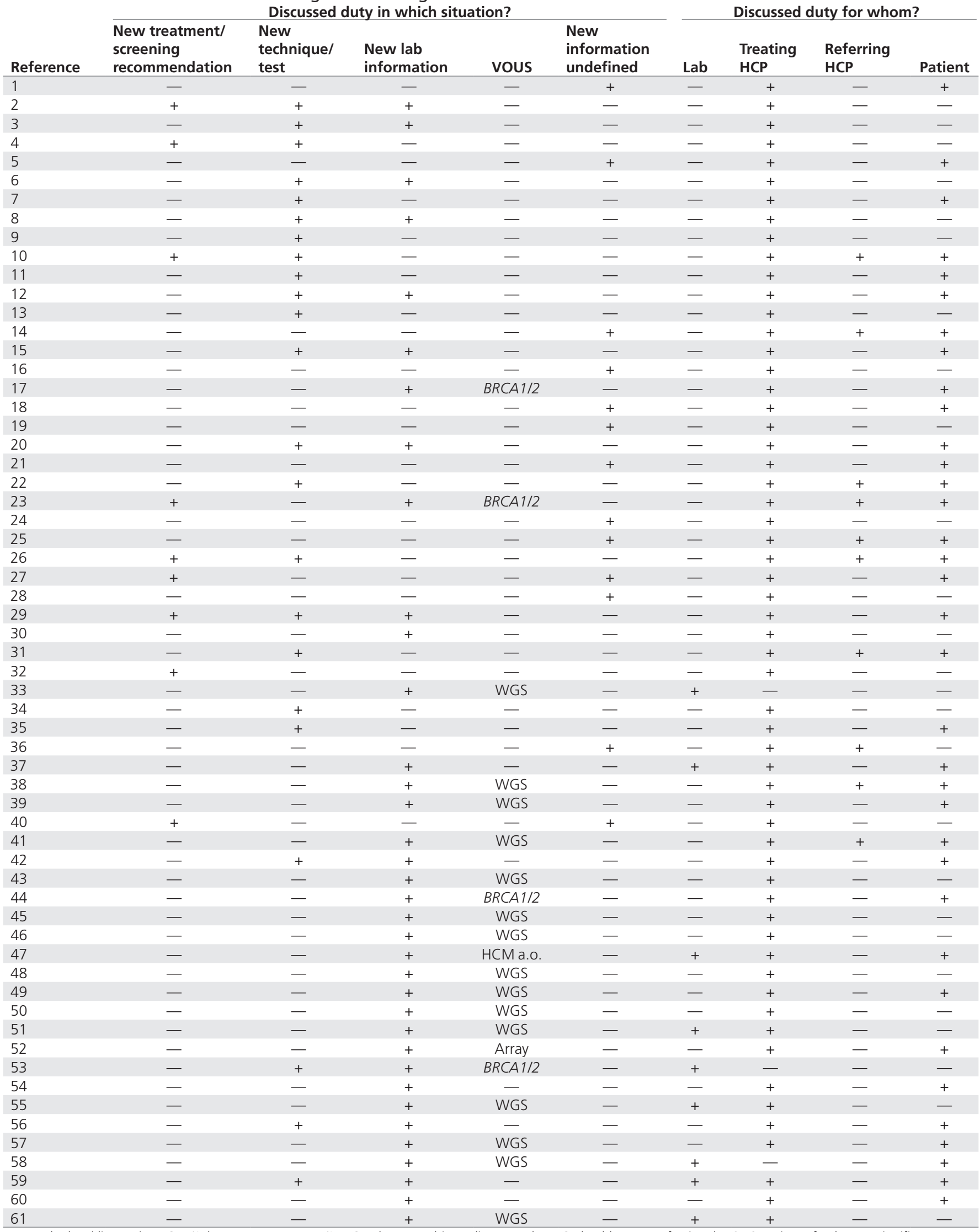


Table $3 \mathrm{ELSI}$ arguments and conclusions regarding duty to recontact in clinical genetics Arguments

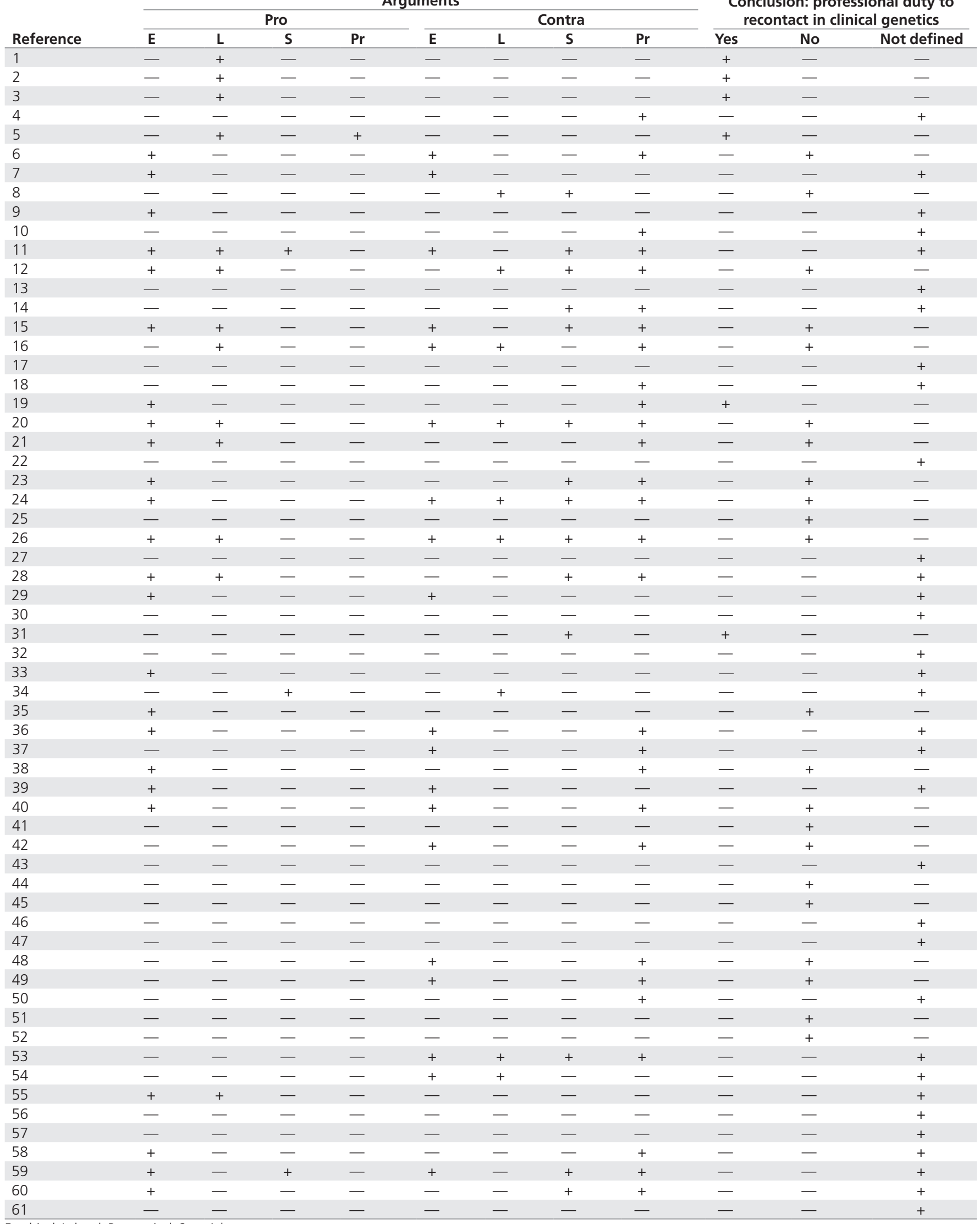


effects on self-image and relationships/family relations. These authors considered that, as long as the psychological consequences of recontacting former patients are unclear, one should be cautious in implementing a recontacting policy. The negative psychological consequences of recontacting former patients regarding relations with their family members, and the consequences for the family members themselves, were mentioned by several authors. ${ }^{8,11,23,29,33,41}$ Because familial implications are an important aspect of genetic counseling and testing in general, these should also be considered in the case of recontacting. In addition to psychological counterarguments, a minority of articles also mentioned other social arguments, for example, financial impact and consequences for insurance. $8,15,30,34$

Ultimately, however, it is the practical aspects, such as knowing which patients to recontact and the availability of an infrastructure for recontacting, that were put forward most often as counterarguments for imposing a duty to recontact. These were the main reasons for many authors to conclude that although recontacting might be desirable, it cannot be regarded as a legal duty.

\section{Recontact in clinical genetics: practical barriers and solutions discussed}

About $75 \%$ of the articles addressed practical barriers to recontacting. Various barriers were distinguished, for example, lack of infrastructure for efficiently tracking files/data of former patients, ${ }^{16,23,42,51,57}$ deciding on/selecting which patients to recontact; ${ }^{24,33,35,37,38}$ lack of time, money, and staff to perform recontacting; $6,11,12,14,15,23,26,36-39,41-43,49,52,57$ and lack of up-to-date patient addresses..$^{10,22,44}$

However, about two-thirds of the articles also mentioned solutions to overcome these barriers. In the older literature about half of the articles that mentioned a solution suggested involving patients in the process of recontacting. ${ }^{1,710,12,18,21,23,25}$ Patients could contribute by, for example, contacting the department regularly to inquire about new genetic information, keep the genetics department up to date regarding address and personal information, and checking for new genetic developments on websites. Fitzpatrick et al. ${ }^{12}$ suggested including informing the media, support groups, and other health professionals in the recontacting process. Establishing databases or computerized registries were also mentioned as possible solutions in several of the older articles. $3,5,6,11,13,14,19$ Ensuring patient privacy was, however, mentioned as a major concern in this respect. Finally, Hunter et al. ${ }^{15,26}$ suggested recording patient preferences regarding recontacting as part of the informed consent procedure at the initial consultation.

In the more recent articles (since 2008), the main solutions being discussed involve communication technologies and (digital) storage of information. ${ }^{38,41-43,45-47,49-51,53-55,58,59}$ Hunt $^{58}$ discussed combining digital storage of patient information and involving patients in the recontacting process by establishing an electronic health system in which patients are in control of their own (WGS) data over time. Several authors also reported on pilot or implemented digital communication systems between laboratories, clinicians, and patients. ${ }^{46,47}$
Wagner et al. ${ }^{61}$ proposed a solution that could avoid largescale recontacting concerning WGS results: Treating WGS like every other diagnostic test by focusing only on the data concerning the actual diagnostic question and discarding all other data avoids a large number of potential recontact-required findings. If a new diagnostic question arises in the future, a new WGS test can be performed. Hastings et $\mathrm{al}^{45}$ also mentioned this approach with regard to privacy/confidentiality issues of patient data storage, relative to the costs of repeating WGS.

\section{Recontact in clinical genetics: duty or not?}

Although the situations authors referred to when discussing a duty to recontact in clinical genetics varied, we tried to score articles by the conclusions given by the authors. Table 3 presents an indication of the extent to which recontacting was considered to be a duty in clinical genetic practice (columns 4-6). Half of the articles drew no clear conclusion about whether recontacting should be considered a duty in clinical genetics. Of the 28 articles that did formulate a conclusion, 6 concluded that a duty to recontact does apply and 22 concluded that it does not.

This scoring should be interpreted with caution because authors' interpretations of what constituted a duty varied. For example, some authors confined the discussion to legal considerations, whereas others focused on broader moral, ethical, or professional duties. All six articles that concluded that there is a duty to recontact in clinical genetics were older articles. Four were written from a legal perspective in the early 1990s by two different researchers. ${ }^{1-3,5}$ They concluded a duty to recontact may be expected in the field of clinical genetics on the basis of US case law on clinical practice in other medical specialties. An often-cited case in this respect is that of Tresemer $v$ Barke, in which a physician was held responsible for not warning his patient of the possible dangers of an intrauterine device when he learned that the device, which he had previously inserted in his patient, was proving dangerous. ${ }^{1,62}$ Andrews, ${ }^{3}$ for example, argued that "courts may hold that professionals who undertake genetic diagnostic procedures, even if they had only a fleeting contact years earlier, have a duty to update patients about subsequently discovered meanings of those tests."

In the fifth article that concluded that a duty to recontact does apply in clinical genetics, Wertz et al. ${ }^{19}$ consider recontacting former patients to be a moral duty and extend this to a responsibility to at-risk family members. They reasoned that a "professional's ethical duty extends beyond those individuals who have presented themselves for care. Ideally, all family members at genetic risk should be informed of all new developments, provided that it is possible to find them and that they are willing to be informed." ${ }^{19}$ Finally, in the sixth article in favor of a duty to recontact in clinical genetics, Rubinstein ${ }^{31}$ discussed recontacting in the context of specific patient groups in certain situations: recontacting to inform breast cancer patients of the availability of chemoprevention; recontacting patients who earlier had not met the criteria for $B R C A 1 / 2$ testing but would do so now; and recontacting to inform patients who had previously been tested for $B R C A 1 / 2$ about the availability of more comprehensive tests 
for $B R C A 1 / 2$. She concluded that in these situations there was a duty to recontact, but recommended careful selection of eligible patients. $^{31}$

In the more recent articles no authors concluded that a duty to recontact in clinical genetics applies. First, it was argued that there are no American or Canadian legal precedents that support a duty to recontact former patients in clinical genetics. ${ }^{20,26,54}$ Although American courts have speculated about the creation of a duty to recontact former patients about subsequently discovered risks, in the more recent literature this speculation was given less support. It was argued that recontacting in light of genetic advances should be regarded as a different legal (and ethical) situation than recontacting because of errors in the application of knowledge or the use of a technical procedure that was valid at the time of initial consultation. ${ }^{26}$ The situations in which a legal duty had been found to apply were all related to side effects of medical interventions instead of new/incidental information from diagnostic or screening tests. ${ }^{54}$ Second, in many articles the clinician's practical ability to fulfill such a duty was questioned. Although a physician's obligation to a patient is to exercise a reasonable degree of care, it was argued that the "nature and scope of a physician's obligations will be adjusted to the particular facts and exigencies of a medical situation." ${ }^{26}$ Therefore, in the field of clinical genetics a "reasonable degree of care" has not yet involved a legal duty to recontact.

In two-thirds of the articles (19 of 29) published since 2008, the duty to recontact was discussed in light of WGS and/or VOUS. The discussion in these articles, however, has shifted from the original recontacting discussion that highlights availability of new treatments or tests to a discussion about the management of complicating/resulting issues of incidental findings and VOUS associated with performing a new test. This complicates the discussion on the duty to recontact yet also puts it in a new light.

\section{Whose duty to recontact is being discussed?}

Table 2 summarizes who was considered to have a duty to recontact. Almost all the articles focused on whether an HCP has a duty toward a patient. In the six articles that concluded a duty to recontact does exist, this was narrowed down to a duty of the treating physician. Ten of 61 articles also suggested that the referring physician had a duty in the process of recontacting former patients with new information. Patient duties were referred to in 33 articles, in which it was reasoned that the responsibility for recontacting should not be limited to the professional level, but instead shared with the patient. Finally, the duties of the laboratory in informing HCPs and patients about new findings or conclusions were discussed in nine recent articles, of which five were about a duty to recontact in light of WGS. $33,51,55,58,61$ Laboratory staff were thought to have a particular duty to keep physicians and counselors up to date on changes in test interpretations so that information could be appropriately offered to patients. Shirts and Parker ${ }^{33}$ discussed the duty of the laboratory directly to the patient in light of direct-to-consumer testing, for which there is no intervening HCP.

\section{Empirical evidence on the duty to recontact}

Ten articles covered in our review provided empirical evidence on recontacting in clinical genetics (Table 4). Four presented their practical experiences with recontacting; ${ }^{9,30,31,35}$ in each case, the recontact was initiated by a clinician from the genetics department by telephone or letter, but three of four studies did not report whether consent for recontacting had been requested at the initial consultation. Despite the difficult consequences that might accompany new information, the majority of patients that participated in these studies were happy to be recontacted because they were now better informed. Some patients, however, expressed negative feelings about being recontacted because it meant they had to cope with new information and/or fears. ${ }^{9,30}$

The other six articles presented data from surveys and focus groups about the implementation of recontacting from the perspective of both counselors and patients. ${ }^{12,14,25,28,49,59}$ These studies described opinions on recontacting as part of standard care; possible benefits, burdens and methods; and professional opinions about using genetic registries for recontacting patients. These data showed that opinions of professionals and patients generally differed on who is responsible for recontacting and on the ethical principles of recontacting. A substantial proportion of patients considered the HCP responsible for updating them about new information and wanted regular contact/recontact. Most professionals considered recontacting to be desirable and the shared responsibility of professionals and patients. Only Townsend et al. ${ }^{49}$ reported on the duty to recontact in light of WGS; patients' and professionals' opinions were in accordance with the other empirical articles.

\section{Existing guidelines on the duty to recontact}

Finally, we examined whether professional guidelines on the duty to recontact exist and what was mentioned in the literature. The only guideline we found was the 1999 policy statement of the American College of Medical Genetics and Genomics on the duty to recontact, ${ }^{10}$ which was referred to by several authors. In this statement the primary-care physician is considered responsible for alerting patients to the need for recontact because medical geneticists do not usually maintain ongoing contact with patients and would therefore have problems relocating and recontacting prior patients. In the 2007 revision of the American College of Medical Genetics and Genomics recommendations for standards for interpreting and reporting sequence variations (referred to by Shirts and Parker ${ }^{33}$ ), it was, however, argued that the position described in the 1999 statement could be problematic for information on novel sequence variants, for example. Because these variants are by definition rare, such knowledge is often restricted to the laboratory. According to the 2007 revision, it was the testing laboratory that should make an effort to contact physicians of previously tested patients if new information changes the initial clinical interpretation of a sequence variant.

The scarcity of guidelines for recontacting in clinical genetics was also apparent from a 2008 review of European countries' 
Table 4 Empirical evidence on the duty to recontact in clinical genetics

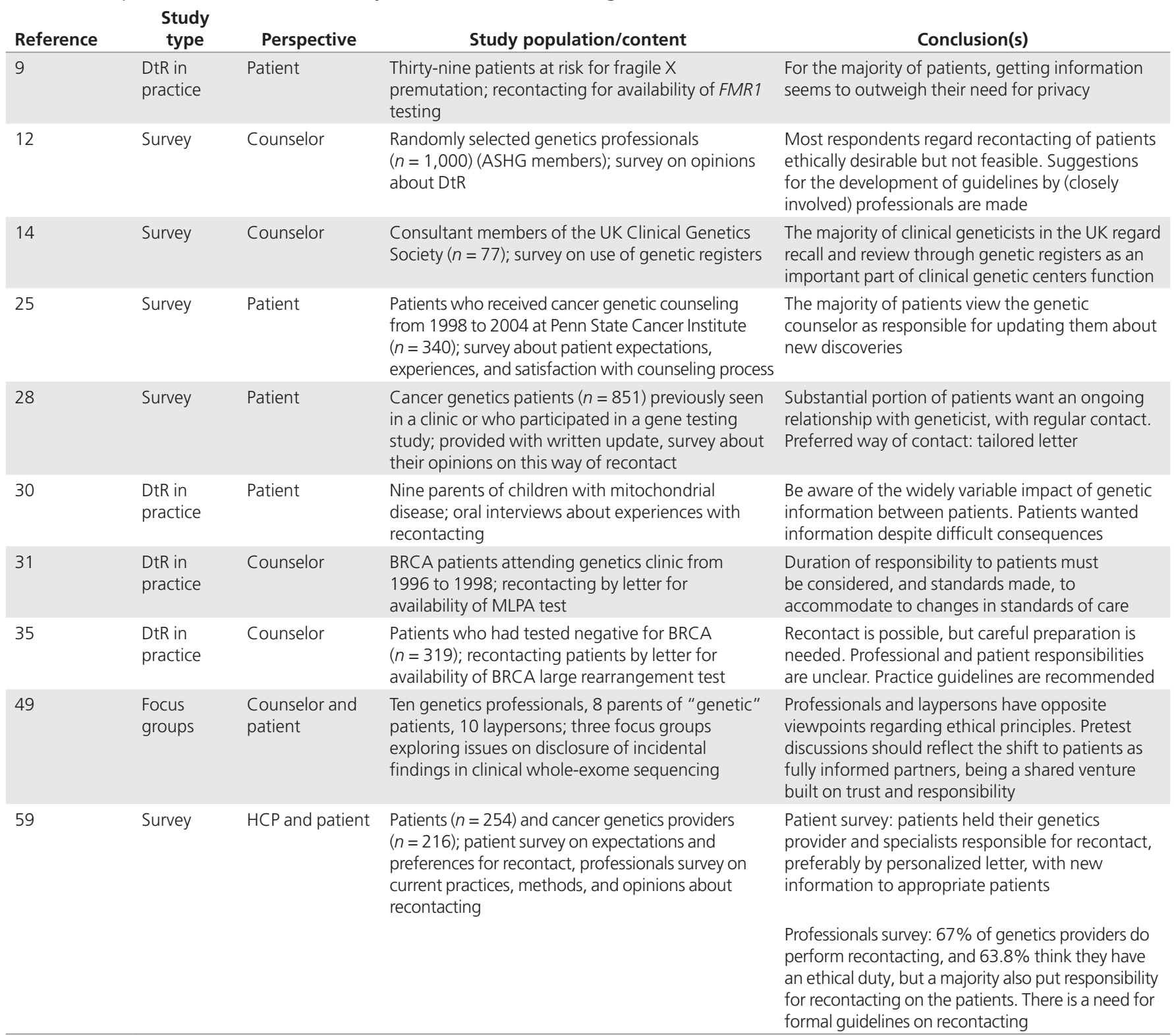

ASHG, American Society of Human Genetics; BRCA, breast cancer; DtR, duty to recontact; FMR1, fragile-X mental retardation 1; MLPA, multiplex ligation-dependent probe amplification.

national regulations and practices of genetic counseling. ${ }^{32}$ This review showed that the application of recontacting in clinical genetic practice was not usually regulated by legislation or mentioned in guidelines and needs further discussion. In addition, two papers referred to two other guidelines when addressing the duty to recontact, ${ }^{28,34}$ but after careful scrutiny neither of these guidelines explicitly addressed the duty to recontact.

\section{DISCUSSION}

\section{Summary}

This systematic review provides an overview of the ELSI as well as practical issues raised in the literature on recontacting former patients in clinical genetic practice and the available empirical evidence. Our review shows that most of the included articles are written from an ethical and clinical perspective. In general, no clear differences between the opinions of authors from different countries or disciplines were apparent, although the few articles that concluded a duty to recontact does exist were written mostly from a legal viewpoint. Most articles discussed recontacting for situations in which new laboratory information related to new test options or techniques becomes available. In the more recent literature the issue of recontacting was also discussed in relation to VOUS and WGS. Ethical and legal arguments were raised both in favor of and against a duty to recontact, whereas social and practical issues were mainly used as counterarguments. Most authors regarded recontacting to be 
ethically desirable, although it was argued that there is no legal basis for a duty to recontact in clinical genetics. Legal precedents are lacking, and recontacting is currently not regarded as a "reasonable degree of care." The greatest obstacles for implementing a general recontacting policy lie in the practical issues, such as tracking and selecting patients, and the time, money, and staff required. Various solutions have, however, been proposed and piloted. Many articles suggest involving patients in the recontacting process; although the responsibility of the treating $\mathrm{HCP}$ is central in the recontacting discussion, many articles stated that the patient also has a responsibility in the recontacting process. Finally, our review shows that empirical evidence and formal guidelines about recontacting in clinical genetics are currently sparse.

\section{Study limitations}

By using broad search terms and a thorough research process, we aimed to make our review as complete as possible. However, we did find 13 references for which no full-text article was available (mostly "gray" literature from Google Scholar), and we excluded three articles not published in English. Furthermore, we will have missed local or national guidelines on the duty to recontact that were not published in peer-reviewed journals. So, despite our thorough approach, we may have missed some relevant articles or information.

\section{Conclusions}

When comparing the discussed situations, arguments, and conclusions of professionals regarding recontacting in the literature, it can be concluded that the weight of ELSI issues in favor of and against recontacting varies for different circumstances and, as a result, the justification for recontacting varies accordingly. This justification seems more obvious for definite and actionable information than for less certain information. A general duty to recontact in clinical genetics will therefore not be applicable. However, future circumstances can be envisaged in which recontacting former patients with new information might be regarded as a "reasonable degree of care."

Furthermore, patient perspectives have to be included in shaping the debate on recontacting in clinical genetics. Although the empirical evidence on implementing a duty to recontact in clinical genetics is sparse, patient experiences that have been described were mainly positive. From another perspective, one can ask how free patients are to decide whether they would like to be recontacted in different circumstances.

Most of the articles we reviewed addressed only the theoretical issue of recontacting and pointed to practical problems as the major challenge. These problems form an important argument against establishing a duty to recontact. Various solutions to overcome these barriers have, however, been raised in the literature. Solutions should also include delineating the roles of all stakeholders and adequate communication between laboratories and clinicians. New digital technologies might offer opportunities for this, and a few successful pilots have already been reported. We recognize, however, that the practical constraints also have an ethical component and that resource restrictions will limit recontacting policies in both these dimensions. Clearly, these issues need to be taken into account when developing professional guidelines.

Finally, there are currently few international guidelines on recontacting former patients when new genetic information becomes available. Further debate is required to determine whether any international guidelines could be sufficient to deal with national and/or local differences in practice or with different national legal systems.

Based on our review, we conclude that there is no generally held legal basis for recontacting in clinical genetics, although it is often considered desirable by both HCPs and patients. General views on the scope of recontacting are unclear, but it was felt that both HCPs and patients should play a role. Patient wishes need to be incorporated in a satisfactory way; some may (temporarily) not wish to hear future updates or new interpretations. Using eHealth technologies in recontacting systems could help solve this issue, but further elaboration on how to best address patient wishes is needed. To make progress in implementing recontacting in clinical genetics, we suggest moving on from the current discussion of whether there is a general duty to recontact in clinical genetics and focusing on the question of in which specific situations recontacting might be regarded as a good standard of care. To this end, we call for a debate between HCPs and patients on future recontacting policies and practices. Moreover, reaching a professional consensus, obtaining more extensive empirical evidence, and developing professional guidelines are important in present-day clinical genetics. These may improve the medical and psychological benefits of new genetic technologies for our patients and their family members.

\section{ACKNOWLEDGMENTS}

We thank Jackie Senior for editing the manuscript.

\section{DISCLOSURE}

The authors declare no conflict of interest.

\section{REFERENCES}

1. Pelias MZ. Duty to disclose in medical genetics: a legal perspective. Am J Med Genet 1991;39:347-354.

2. Andrews LB. Legal aspects of genetic information. Yale J Bio/ Med 1991;64: 29-40.

3. Andrews LB. Torts and the double helix: malpractice liability for failure to warn of genetic risks. Houst Law Rev 1992;29:149-184.

4. Hecht F. Duty to disclose to family members in medical genetics. Am J Med Genet 1992;42:758-760.

5. Pelias MZ. The duty to disclose to relatives in medical genetics - response. Am J Med Genet 1992;42:759-760.

6. Patenaude AF. The genetic testing of children for cancer susceptibility: ethical, legal, and social issues. Behav Sci Law 1996;14:393-410.

7. Almqvist $E$, Adam S, Bloch M, Fuller A, Welch P. Risk reversals in predictive testing for Huntington disease. Am J Hum Genet 1997;61:945-952.

8. Andrews LB. The genetic information superhighway: rules of the road for contacting relatives and recontacting former patients. In: Knoppers BM (ed). Human DNA: Law and Policy: International and Comparative Perspectives? Kluwer Law International: The Hague, The Netherlands, 1997:133-143.

9. Bernard LE, McGillivray B, Van Allen MI, Friedman JM, Langlois S. Duty to re-contact: a study of families at risk for Fragile X. J Genet Couns 1999; $8: 3-15$. 
10. Hirschhorn K, Fleisher LD, Godmilow L, et al. Duty to re-contact. Genet Med 1999;1:171-172; erratum 1:186.

11. Sharpe NF. The duty to recontact: benefit and harm. Am J Hum Genet 1999;65:1201-1204.

12. Fitzpatrick JL, Hahn C, Costa T, Huggins MJ. The duty to recontact: attitudes of genetics service providers. Am J Hum Genet 1999;64:852-860.

13. Harris R, Harris H. Knowledge about medical genetics in health care. Community Genet 1999;2:115-117.

14. Dean JC, Fitzpatrick DR, Farndon PA, Kingstn H, Cusine D. Genetic registers in clinical practice: a survey of UK clinical genetics. J Med Genet 2000;37: 636-640.

15. Hunter AG, Sharpe N, Mullen M, Meschino WS. Ethical, legal, and practical concerns about recontacting patients to inform them of new information: the case in medical genetics. Am J Med Genet 2001;103:265-276.

16. Knoppers BM. Editorial comment: duty to recontact: a legal harbinger? Am J Med Genet 2001;103:277.

17. Peshkin BN, DeMarco TA, Brogan BM, Lerman C, Isaacs C. BRCA1/2 testing: complex themes in result interpretation. J Clin Oncol 2001;19:2555-2565.

18. Godard B, Kääriäinen $\mathrm{H}$, Kristoffersson U, Tranebjaerg L, Coviello D, Aymé S. Provision of genetic services in Europe: current practices and issues. Eur J Hum Genet 2003;11(suppl 2):S13-S48.

19. Wertz DC, Fletcher JC, Berg K. Review of Ethical Issues in Medical Genetics. Report of Consultants to WHO. World Health Organization, Human Genetics Programme: Geneva, Switzerland, 2003.

20. Letendre M, Godard B. Expanding the physician's duty of care: a duty to recontact? Med Law 2004;23:531-539.

21. Doheny DO, Leon de D, Raymond D. Genetic testing and counseling. In: Brin MF, Comella C, Jankovic J (eds). Dystonia: Etiology, Clinical Features and Treatment. Lippincott Williams \& Wilkins: Philadelphia, PA, 2004:23-32.

22. Milunsky A, Milunsky JM. Genetic counseling: preconception, prenatal and perinatal. In: Milunsky A (ed). Genetic Disorders and the Fetus: Diagnosis, Prevention and Treatment. JHU Press: Baltimore, MD, 2004:1-65.

23. Brown KL, Moglia DM, Grumet S. Genetic counseling for breast cancer risk: general concepts, challenging themes and future directions. Breast Dis 2006;27:69-96.

24. Guzauskas GF, Lebel RR. The duty to re-contact for newly appreciated risk factors: fragile X premutation. J Clin Ethics 2006;17:46-52.

25. Kausmeyer DT, Lengerich EJ, Kluhsman BC, Morrone D, Harper GR, Baker MJ. A survey of patients' experiences with the cancer genetic counseling process: recommendations for cancer genetics programs. J Genet Couns 2006;15:409-431.

26. Hunter A, Sharpe NF, Mullen M, Meschino WS. Ethical, legal, and practical concerns about recontacting patients to inform them of new information: the case in medical genetics. In: Sharpe NF, Carter RF (eds). Genetic Testing: Care, Consent and Liability. Wiley: Hoboken, NJ, 2006:415-424.

27. Nagaraja SM, Jain S, Muthane UB. Perspectives towards predictive testing in Huntington disease. Neurol India 2006;54:359-362.

28. Griffin CA, Axilbund JE, Codori AM, et al. Patient preferences regarding recontact by cancer genetics clinicians. Fam Cancer 2007;6:265-273.

29. Peshkin BN, Burke, W. Bioethics of genetic testing for hereditary breast cancer. In: Isaacs C, Rebbeck TR (eds). Hereditary Breast Cancer. Informa Healthcare USA: New York, 2007:35-49.

30. Sexton AC, Sahhar M, Thorburn DR, Metcalfe SA. Impact of a genetic diagnosis of a mitochondrial disorder 5-17 years after the death of an affected child. $J$ Genet Couns 2008;17:261-273.

31. Rubinstein WS. Roles and responsibilities of a medical geneticist. Fam Cancer 2008;7:5-14.

32. Rantanen $E$, Hietala $M$, Kristoffersson $U$, et al. Regulations and practices of genetic counselling in 38 European countries: the perspective of national representatives. Eur J Hum Genet 2008;16:1208-1216.

33. Shirts BH, Parker LS. Changing interpretations, stable genes: responsibilities of patients, professionals, and policy makers in the clinical interpretation of complex genetic information. Genet Med 2008;10:778-783.

34. Sexton AC, Metcalfe SA. Disclosing genetic research results after death of pediatric patients. JAMA 2008;300:1693-1695.

35. Hampel H. Recontacting patients who have tested negative for BRCA1 and BRCA2 mutations: how, who and why? J Genet Couns 2009;18:527-529.

36. Mezer E, Wygnanski-Jaffe T. Ethical issues in ocular genetics. Curr Opin Ophthalmol 2009;20:382-386.

37. Resta RG. Unprepared, understaffed, and unplanned: thoughts on the practical implications of discovering new breast and ovarian cancer causing genes. J Genet Couns 2009;18:521-523.
38. Ali-Khan SE, Daar AS, Shuman C, Ray PN, Scherer SW. Whole genome scanning: resolving clinical diagnosis and management amidst complex data. Pediatr Res 2009;66:357-363.

39. Dondorp WJ, De Werth GMWR. Health Council of the Netherlands. The 'thousand-dollar genome': an ethical exploration. Monitoring Report Ethics and Health 2010/2. Centre for Ethics and Health: The Hague, The Netherlands, 2010.

40. Elger B, Michaud K, Mangin P. When information can save lives: the duty to warn relatives about sudden cardiac death and environmental risks. Hastings Cent Rep 2010;40:39-45.

41. Pyeritz RE. The coming explosion in genetic testing-is there a duty to recontact? NEng/ J Med 2011;365:1367-1369.

42. Sijmons RH, Van Langen IM, Sijmons JG. A clinical perspective on ethical issues in genetic testing. Account Res 2011;18:148-162.

43. Sharp RR. Downsizing genomic medicine: approaching the ethical complexity of whole-genome sequencing by starting small. Genet Med 2011;13: 191-194.

44. Murray ML, Cerrato F, Bennett RL, Jarvik GP. Follow-up of carriers of BRCA1 and BRCA2 variants of unknown significance: variant reclassification and surgical decisions. Genet Med 2011;13:998-1005.

45. Hastings R, de Wert G, Fowler B, et al. The changing landscape of genetic testing and its impact on clinical and laboratory services and research in Europe. Eur J Hum Genet 2012;20:911-916.

46. Trakadis YJ. Patient-controlled encrypted genomic data: an approach to advance clinical genomics. BMC Med Genomics 2012;5:31.

47. Aronson SJ, Clark EH, Varugheese M, Baxter S, Babb LJ, Rehm HL. Communicating new knowledge on previously reported genetic variants. Genet Med 2012;14:713-719.

48. Thorogood A, Knoppers BM, Dondorp WJ, de Wert GM. Whole-genome sequencing and the physician. Clin Genet 2012;81:511-513.

49. Townsend A, Adam S, Birch PH, Lohn Z, Rousseau F, Friedman JM. "I want to know what's in Pandora's Box": comparing stakeholder perspectives on incidental findings in clinical whole genomic sequencing. Am J Med Genet $A$ 2012;158A:2519-2525.

50. Van El CG, Cornel MC, Borry P, et al. Whole-genome sequencing in health care. Recommendations of the European Society of Human Genetics. Eur J Hum Genet 2013;21:580-584.

51. Vanakker OM, De Paepe A. Pharmacogenomics in children: advantages and challenges of next generation sequencing applications. Int J Pediatr 2013;2013:136524.

52. Reiff M, Ross K, Mulchandani S, et al. Physicians' perspectives on the uncertainties and implications of chromosomal microarray testing of children and families. Clin Genet 2013;83:23-30.

53. Bean LJ, Tinker SW, da Silva C, Hegde MR. Free the data: one laboratory's approach to knowledge-based genomic variant classification and preparation for EMR integration of genomic data. Hum Mutat 2013;34:1183-1188.

54. Clayton EW, Haga S, Kuszler P, Bane E, Shutske K, Burke W. Managing incidental genomic findings: legal obligations of clinicians. Genet Med 2013;15: 624-629.

55. Hazin R, Brothers KB, Malin BA, et al. Ethical, legal, and social implications of incorporating genomic information into electronic health records. Genet Med 2013;15:810-816.

56. Quaid KA. Molecular testing: ethical and legal issues. In: Cheng L, Zhang DY, Eble JN (eds). Molecular Genetic Pathology. Springer Science and Business Media: New York, 2013:1083-1090.

57. Ayuso C, Millán JM, Mancheño M, Dal-Ré R. Informed consent for whole-genome sequencing studies in the clinical setting. Proposed recommendations on essential content and process. Eur J Hum Genet 2013; 21:1054-1059.

58. Hunt K. Individualizing the informed consent process for whole genome sequencing: a patient directed approach. Dissertation, Arizona State University: Phoenix, Arizona, 2013.

59. O'Connor MR. Patient and genetics health care providers attitudes regarding recontact. Thesis, University of Pittsburgh: Pittsburgh, PA, 2014.

60. Semaka A, Hayden MR. Evidence-based genetic counselling implications for Huntington disease intermediate allele predictive test results. Clin Genet 2014;85:303-311.

61. Wagner JK, Mozersky JT, Pyeritz RE. "Use it or lose it" as an alternative approach to protect genetic privacy in personalized medicine. Urol Oncol 2014;32: 198-201.

62. Berg D, Hirsh HL. Duty to recall. South Med J 1980;73:1041-3, 1045. 